\footnotetext{
JURNAL CEMERLANG: Pengabdian pada Masyarakat

P-ISSN 2654-4741 / E-ISSN 2655-7894

Vol. 4, No. 1, Desember 2021, 22 - 32

DOI: https://doi.org/10.31540/jpm.v4i1.1292

PENERBIT: LP4MK STKIP PGRI LUBUKLINGGAU
}

\title{
PELATIHAN PEMBUATAN DAN PEMASARAN ZPT ALAMI DI KELURAHAN CAWANG BARU KECAMATAN SELUPU REJANG
}

\author{
Ria Dwi Jayati ${ }^{1}$, Nur Fitriyana ${ }^{2}$ \\ ${ }^{1}$ Program Studi Pendidikan Biologi, STKIP PGRI Lubuklinggau \\ ${ }^{2}$ Program Studi Pendidikan Matematika, STKIP PGRI Lubuklinggau \\ Jalan Mayor Toha Kelurahan Air Kuti, Kota Lubuklinggau, 31628, Indonesia \\ Email: ria2jayati@gmail.com
}

\begin{abstract}
ABSTRAK
Program Kemitraan Masyarakat (PKM) yang kami usulkan diharapkan dapat membantu masyarakat Kelurahan Cawang Baru pada umumnya dan kelompok IRT Adelia pada khususnya dalam pembuatan dan pemasaran Zat Perangsang Tumbuh (ZPT) alami. Kelurahan Cawang Baru yang terdapat di Kecamatan Selupu Rejang merupakan daerah pertanian yang banyak menghasilkan berbagai macam jenis komoditas tanaman pertanian. Disamping fakta tersebut, saat ini juga sedang marak sekali masyarakat penghobi bunga khususnya ibu-ibu. Selama ini petani dan juga para penghobi tanaman hias di Kelurahan Cawang baru dalam budidaya atau memperbanyak tanaman selain menggunakan pupuk juga menggunakan ZPT yang dijual di pasaran, harga ZPT pabrikan di pasaraan lumayan mahal dan sedikit sulit didapatkan di toko-toko pertanian konvensional karena kandungannya yang tidak alami bisa saja memberikan efek buruk terhadap lingkungan. Mengingat biaya yang harus dikeluarkan untuk membeli ZPT kimiawi dan dampak buruknya terhadap lingkungan, membuat ZPT sendiri dengan memanfaatkan bahan alami yang ada di sekitar menjadi solusi yang tepat untuk menangani masalah biaya dan dampak lingkungan. Untuk mencapai tujuan tersebut, kami menggunakan metode observasi, sosialisasi, pelatihan dan dilanjutkan dengan praktek langsung. Tujuan jangka panjang kegiatan ini adalah menciptakan peluang usaha bagi kelompok PKK Adelia dengan memanfaatkan bahan alami sebagai ZPT yang keberadaannya dibutuhkan petani dan penghobi tanaman hias. Target luaran dari kegiatan adalah (1) pengetahuan, keterampilan dan penghasilan mitra meningkat, (2) menghasilkan produk ZPT alami. Target luaran publikasi: hasil pengabdian dipublikasikan pada jurnal pengabdian masyarakat.
\end{abstract}

ABSTRACK

The Community Partnership Program that we propose is expected to help the Cawang Baru Village community in general and the Adelia IRT group in particular in the manufacture and marketing of natural Growth Stimulating Substances (PGR). Cawang Baru Village located in Selupu Rejang District is an agricultural area that produces many types of agricultural crop commodities. Besides these facts, there is also a lot of people who love flowers, especially mothers. So far, farmers and ornamental plant hobbyists in Cawang Village are new to cultivating or multiplying plants in addition to using fertilizers but also using PGR sold in the market, the price of manufactured PGR in the market is quite expensive and a little difficult to find in conventional agricultural shops because of its low content naturally can have a negative effect on the environment. Considering the costs involved in buying chemical PGR and its negative impact on the environment, making your own PGR by utilizing natural materials that are around is the right solution to deal with the problem of costs and environmental impacts. To achieve this goal, we used the method of observation, socialization, training and continued with direct practice. The long-term goal of this activity is to create business opportunities for the PKK Adelia group by utilizing natural materials as PGR whose existence is needed by farmers and ornamental plant hobbyists. The output targets of the activity are (1) increasing partners' knowledge, skills and income, (2) producing natural PGR products. Publication output target: service results published in community service journals. 
JURNAL CEMERLANG: Pengabdian pada Masyarakat
P-ISSN 2654-4741 / E-ISSN 2655-7894
Vol. 4, No. 1, Desember 2021, 22-32
DOI: https://doi.org/10.31540/jpm.v4i1.1292
PENERBIT: LP4MK STKIP PGRI LUBUKLINGGAU

KEYWORDS

Pelatihan, Pembuatan, Pemasaran, ZPT

Training, Manufacturing, Marketing, ZPT
ARTICLE HISTORY

Received 07 Juli 2021

Revised 18 September 2021

Accepted 23 November 2021

CORRESPONDENCE Ria Dwi Jayati@ ria2jayati@gmail.com

\section{PENDAHULUAN}

Kelurahan Cawang Baru Kecamatan Selupu Rejang Kabupaten Rejang Lebong Provinsi Bengkulu merupakan daerah penghasil berbagai macam komoditas tanaman pertanian. Kabupaten Rejang Lebong selain sebagai daerah sentra pertanian, juga memiliki berbagai potensi dan daya tarik wisata yang dapat dikembangkan untuk menarik wisatawan dan menikmati kekayaan alam dan budaya Kabupaten Rejang Lebong (rejanglebongkab.go.id). Di Kelurahan Cawang Baru terdapat kelompok PKK yang dibentuk secara mandiri, anggota dari kelompok PKK ini merupakan ibu-ibu rumah tangga yang suaminya Sebagian berprofesi sebagai petani. Kelompok PKK ini bernama kelompok PKK Adelia.

Kelompok PKK yang diketuai oleh Ibu Yeni memiliki anggota sebanyak 10 orang yang semuanya merupakan ibu-ibu rumah tangga yang ikut aktif membantu suaminya bercocok tanam. Kerena dibentuk secara mandiri dan belum lama berdiri, kelompok wanita tani ini belum pernah mendapatkan sosialisasi dan penyuluhan yang mengarah pada pembuatan ZPT alami dan pemasarannya.

Peluang usaha yang dapat dilakukan oleh kelompok PKK ini yaitu membuat ZPT alami dari campuran air kelapa, bawang merah, tauge dan rebung bambu. Tidak banyak masyarakat yang tahu bahwa air kelapa, bawang merah, tauge dan rebung bambu bisa dijadikan sebagai ZPT hormon penyubur tanaman. ZPT yang dihasilkan dapat digunakan sebagai bahan yang dapat mendukung pertumbuhan dan mempercepat perbanyakan tanaman secara vegetative seperti stek, cangkok dan okulasi.

ZPT alami yang dihasilkan dapat diperjualbelikan kepada para petani dan penghobi tanaman atau dititipkan pada toko-toko pertanian dengan harga yang 


\section{JURNAL CEMERLANG: Pengabdian pada Masyarakat \\ P-ISSN 2654-4741 / E-ISSN 2655-7894 \\ Vol. 4, No. 1, Desember 2021, 22 - 32 \\ DOI: https://doi.org/10.31540/jpm.v4i1.1292 \\ PENERBIT: LP4MK STKIP PGRI LUBUKLINGGAU}

kompetitif. Dengan demikian produk berupa ZPT ini dapat juga menambah pendapatan bagi Kelompok PKK. Hasil penjualan ZPT ini nantinya akan diolah oleh sesama anggota kelompok PKK untuk kesejahteraan anggota dan kemajuan kelompok PKK itu sendiri.

Kelompok PKK dalam menjalankan usaha ini tidak membutuhkan waktu yang khusus sehingga tidak mengganggu aktivitas rutin harian, pengerjaannya fleksibel dan mudah. Selain mudah, usaha sampingan ini akan membantu perekonomian anggota kelompok PKK karena dalam prosesnya bahan baku diperoleh secara murah bahkan gratis dengan memanfaatkan bahan alami yang ada disekitar. Namun dalam melakukan kegiatan ini kelompok PKK menghadapi beberapa persoalan diantaranya sumberdaya manusia. Sumber daya manusia yang dimaksud dalam hal ini yaitu kemampuan untuk menciptakan dan mengolah bahan alami menjadi produk ZPT. Dari hasil observasi di lapangan petani dan Penghobi tanaman hanya memanfaatkan ZPT pabrikan untuk memenuhi kebutuhan hormone pada tanaman budidaya yang dibeli di toko-toko pertanian dengan harga yang relatif mahal. Persoalan selanjutnya yaitu belum tersedianya peralatan penunjang proses pembuatan ZPT. Setelah produk ZPT alami dihasilkan, timbul permasalahan baru mengenai cara pemasaran produk yang belum dikuasai oleh kelompok PKK.

Permasalahan yang dihadapi oleh kelompok PKK adalah kurangnya pemahaman dalam mengelola bawang merah, tauge dan rebung bambu menjadi ZPT alami. Dengan demikian kelompok PKK perlu dibekali dengan ilmu pengetahuan dan teknologi tepat guna sehingga dapat diterapkan dalam kegiatan. Dalam proses pembuatan ZPT alami hal yang menjadi permasalahan yaitu ketersediaan alat penunjang. Permasalahan lain yang muncul ketika produk dalam bentuk ZPT sudah dihasilkan yaitu proses pemasaran produk yang akan dilakukan oleh anggota kelompok PKK. 


\section{JURNAL CEMERLANG: Pengabdian pada Masyarakat \\ P-ISSN 2654-4741 / E-ISSN 2655-7894 \\ Vol. 4, No. 1, Desember 2021, 22 - 32 \\ DOI: https://doi.org/10.31540/jpm.v4i1.1292 \\ PENERBIT: LP4MK STKIP PGRI LUBUKLINGGAU}

\section{METODE}

Untuk mencapai target yang diharapkan, tim dari STKIP PGRI Lubuklinggau melaksanakan kegiatan PKM dengan dua tahapan yaitu: (1) tahap persiapan, dan; (2) tahap pelatihan dan pelaksanaan.

\section{Tahap Persiapan}

Tahap persiapan diawali dengan kegiatan observasi dengan mengunjungi lokasi mitra yang terdapat di Kelurahan Cawang Baru Kecamatan Selupu Rejang Kabupaten Rejang Lebong, pada kegiatan ini tim PKM mencoba mengumpulkan data informasi tentang sumber daya alam dan sumberdaya manusia yang ada di Kelurahan Cawang Baru melalui pengamatan dan wawancara langsung kepada warga masyarakat dan pihak-pihak terkait. Setelah data dan informasi yang dibutuhkan terkumpul melalui kegiatan observasi, tim PKM selanjutnya melakukan koordinasi dengan kelompok PKK Adelia yang menjadi mitra pada kegiatan ini untuk membahas kegiatan sosialisasi, dan pelatihan terkait dengan pembuatan dan pemasaran ZPT alami. Sosialisasi dilakukan kepada kelompok PKK Adelia dengan memberikan pengetahuan dan wawasan mitra yang menekankan pada penyampaian materi tentang:

a. Bahaya bahan kimia dan peluang bahan alami di lingkungan sekitar menjadi produk bernilai jual dan ramah lingkungan. Melalui kegiatan ini diharapkan mitra memiliki pengetahuan tentang bahaya bahan kimia dan peluang bahan alami di lingkungan sekitar menjadi produk bernilai jual dan ramah lingkungan.

b. Upaya yang dapat dilakukan untuk membatasi penggunaan ZPT pabrikan melalui teklologi tepat guna yaitu teknologi pembuatan ZPT alami. Hasil dari kegiatan ini diharapkan mitra memiliki pemahaman tentang upaya yang dapat dilakukan untuk membatasi penggunaan ZPT pabrikan melalui teklologi tepat guna yaitu teknologi pembuatan ZPT alami.

c. Cara pemasaran produk ZPT. Dari kegiatan ini diharapkan mitra memiliki pengetahuan tentang cara memasarkan produk yang berupa zat 


\section{JURNAL CEMERLANG: Pengabdian pada Masyarakat \\ P-ISSN 2654-4741 / E-ISSN 2655-7894 \\ Vol. 4, No. 1, Desember 2021, 22 - 32 \\ DOI: https://doi.org/10.31540/jpm.v4i1.1292 \\ PENERBIT: LP4MK STKIP PGRI LUBUKLINGGAU}

perangsang tumbuh (ZPT) alami dan bagaimana namajemen usahanya sehingga mitra dapat mengelola dengan baik hasil dari penjualan produk secara berkelanjutan.

2. Tahap Pelatihan dan Pelaksanaan

Tahap pelatihan dan pelaksanaan yang dilakukan oleh tim PKM diharapkan membuat mitra memiliki keterampilan dalam membuat produk ZPT dan manajemen pemasarannya. Adapun rincian dari kegiatan dari tahap pelatihan dan pelaksanaan kegiatan PKM adalah sebagai berikut:

a. Tim PKM melakukan kegiatan pelatihan tentang cara membuat ZPT. Dari kegiatan ini tujuan yang akan dicapai yaitu peserta pelatihan dapat memahami teknologi tepat guna dalam memanfaatkan bahan alami dengan melakukan pembuatan ZPT.

b. Tim PKM melakukan kegiatan pengadaan peralatan dan bahan penunjang yang akan digunakan untuk membuat ZPT. Tujuan yang akan dicapai dari kegiatan ini yaitu mitra dapat mempraktekkan proses pembuatan ZPT karena alat dan bahan tersedia.

c. Tim PKM melakukan kegiatan pendampingan pada saat proses pembuatan ZPT. Tujuan yang akan dicapai dari kegiatan ini yaitu mitra dapat melakukan kegiatan pembuatan ZPT di bawah bimbingan dan pengawasan tim PKM sehingga mempermudah mitra untuk bertanya jika ada yang kurang dipahami, kegiatan pendampingan ini dilakukan secara langsung di lapangan ketika kegitan berlangsung dan juga melalui media telekomunikasi baik melalui telepon maupun aplikasi WhatsApp karena proses pembuatan ZPT ini memakan waktu yang cukup lama sehingga pemantauan langsung tidak bisa dilakukan sepanajng waktu.

d. Tim PKM bersama mitra melakukan kegiatan pengemasan produk dan pemasaran. Tujuan dari kegiatan ini yaitu mitra dapat mempersiapkan proses pemasaran produk dengan baik dan matang. 


\section{JURNAL CEMERLANG: Pengabdian pada Masyarakat \\ P-ISSN 2654-4741 / E-ISSN 2655-7894 \\ Vol. 4, No. 1, Desember 2021, 22 - 32 \\ DOI: https://doi.org/10.31540/jpm.v4i1.1292 \\ PENERBIT: LP4MK STKIP PGRI LUBUKLINGGAU}

3. Metode Pendekatan

Metode pendekatan yang ditawarkan untuk menyelesaikan persoalan ini yaitu melalui:

a. Sosialisasi untuk menumbuhkan rasa peduli lingkungan dan menumbuhkan jiwa wirausaha serta penerapan teknologi tepat guna dalam penggunaan bahan alami dan berpotensi menjadi peluang usaha yang pembuatan ZPT.

b. Pendekatan keterampilan melalui pemberian pelatihan kepada mitra dalam pembuatan ZPT dan juga manajemen pemasaran produknya.

4. Partisipasi Mitra

Dalam pelaksanaan PKM ini partisipasi mitra diantaranya yaitu sebagai berikut:

a. Peserta sosialisasi dan pelatihan

b. Penyedia tempat sosialisasi dan pelatihan

c. Penyedia lokasi pembuatan ZPT

d. Penyedia bahan baku ZPT

5. Evaluasi Pelaksanaan dan Keberlanjutan Program

a. Langkah Evaluasi Pelaksanaan Program

Evaluasi pelaksanaan program dilakukan selama periode kegiatan PKM berlangsung agar program berjalan sesuai dengan apa yang telah direncanakan. Kegiatan evaluasi pelaksanaan program meliputi pemantauan kerja sama tim, pemantauan alat dan ketersediaan bahan baku pembuat ZPT, pemantauan tempat sosialisasi dan lokasi pembuatan ZPT serta pemantauan proses pembuatan ZPT, pengemasan dan pemasarannya.

b. Langkah Evaluasi Keberlanjutan Program di Lapangan Setelah Kegiatan PKM Selesai Dilaksanakan 


\section{JURNAL CEMERLANG: Pengabdian pada Masyarakat \\ P-ISSN 2654-4741 / E-ISSN 2655-7894 \\ Vol. 4, No. 1, Desember 2021, 22 - 32 \\ DOI: https://doi.org/10.31540/jpm.v4i1.1292 \\ PENERBIT: LP4MK STKIP PGRI LUBUKLINGGAU}

Evaluasi keberlanjutan program di lapangan dilakukan setelah kegiatan PKM selesai dilaksanakan dan dilanjutkan sampai mitra dapat menjalankan kegiatan dengan baik tanpa pendampingan.

\section{HASIL dan PEMBAHASAN}

Hasil dari kegiatan Program Pengabdian Masyarakat (PKM) tentang pembuatan dan pemasaran produk ZPT alami ini adalah:

1. Mitra memiliki pengetahuan tentang bahaya bahan kimia dan peluang bahan alami di lingkungan sekitar menjadi produk bernilai jual dan ramah lingkungan. Dengan kegiatan ini mitra memiliki pengetahuan tentang bahaya bahan kimia dalam produk pertanian baik bagi mahluk hidup maupun lingkungan dan mitra memiliki pengetahuan tentang peluang bahan alami yang ada di sekitar lingkungan mitra untuk dapat diolah menjadi produk pertanian dengan nilai ekonomi cukup tinggi dan tidak mencemari lingkungan, yaitu berupa produk ZPT alami. Di bawah ini adalah gambar grafik peningkatan pengatahuan mitra dari 6 orang respinden pada saat sebelum dan setelah mendapatkan sosialisasi dan pelatihan (gambar 1) dan gambar dokumentasi kegiatan pada saat sosialisasi (gambar 2).

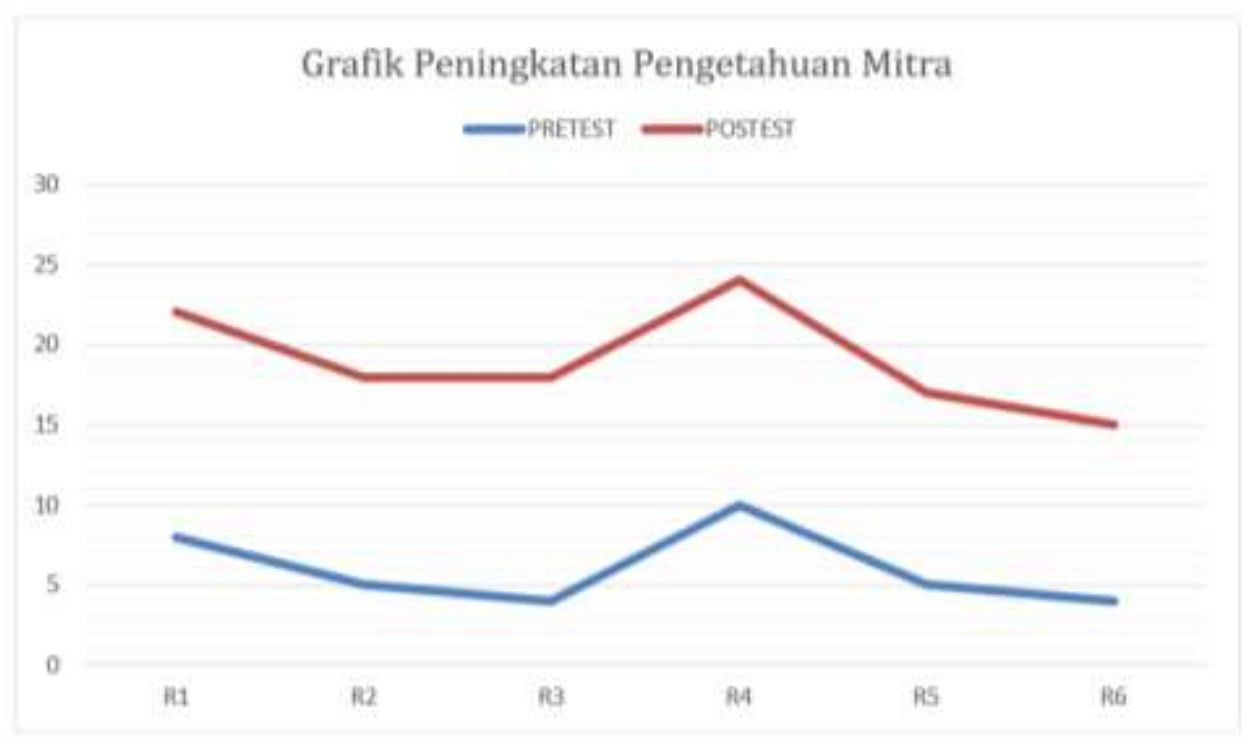

Gambar 1. Grafik peningkatan pengetahuan mitra 


\section{JURNAL CEMERLANG: Pengabdian pada Masyarakat}

P-ISSN 2654-4741 / E-ISSN 2655-7894

Vol. 4, No. 1, Desember 2021, 22 - 32

DOI: https://doi.org/10.31540/jpm.v4i1.1292

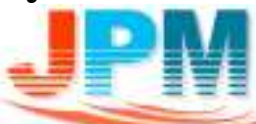

PENERBIT: LP4MK STKIP PGRI LUBUKLINGGAU

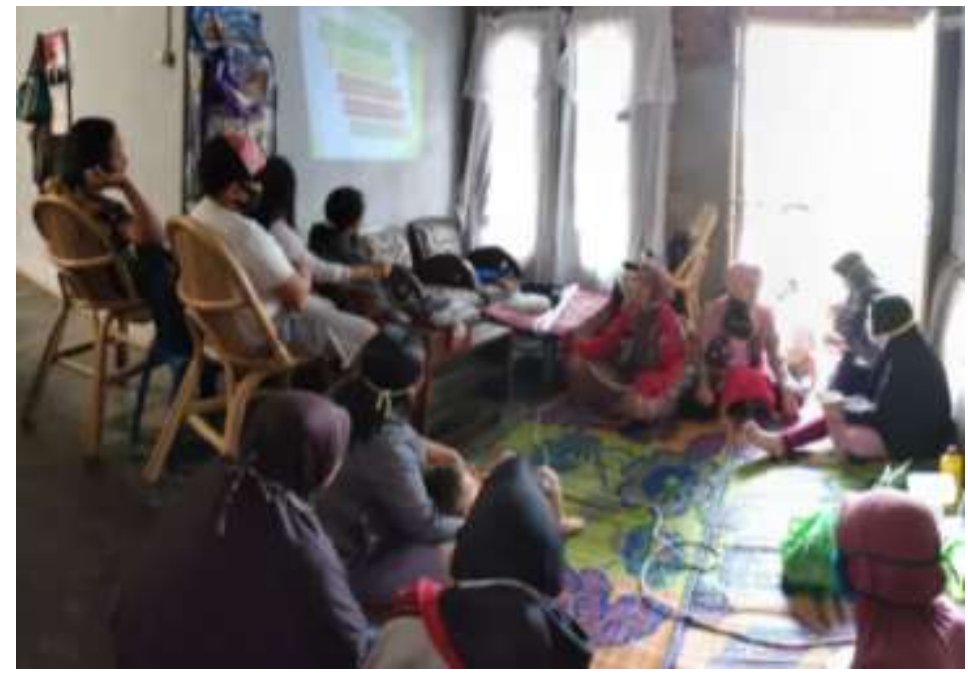

Gambar 2. Penyampaian materi oleh narasumber kepada mitra

2. Mitra memiliki pengetahuan dan keterampilan tentang cara membuat ZPT alami dari bahan alami yang ada di sekitar lokasi tempat tinggal mitra. Mitra yang selama ini tidak mengetahui manfaat lain (sebagai bahan baku ZPT) bahan alami yang ada disekitarnya seperti bawang merah, kecambah dan rebung yang selama ini hanya diketahui sebagai bahan masakan, kini mulai mengetahui bahwa bahan-bahan tersebut juga dapat menjadi bahan baku dalam pembuatan ZPT yang berguna untuk merangsang pertumbuhan tanaman.

\section{Grafik Peningkatan Keterampilan Mitra}

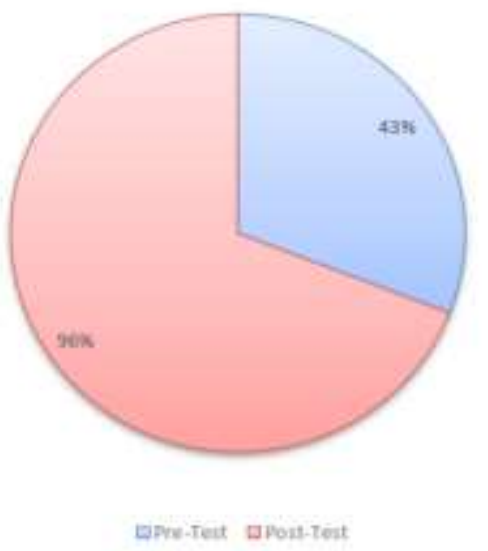

Gambar 3 Grafik peningkatan keterampilan mitra 

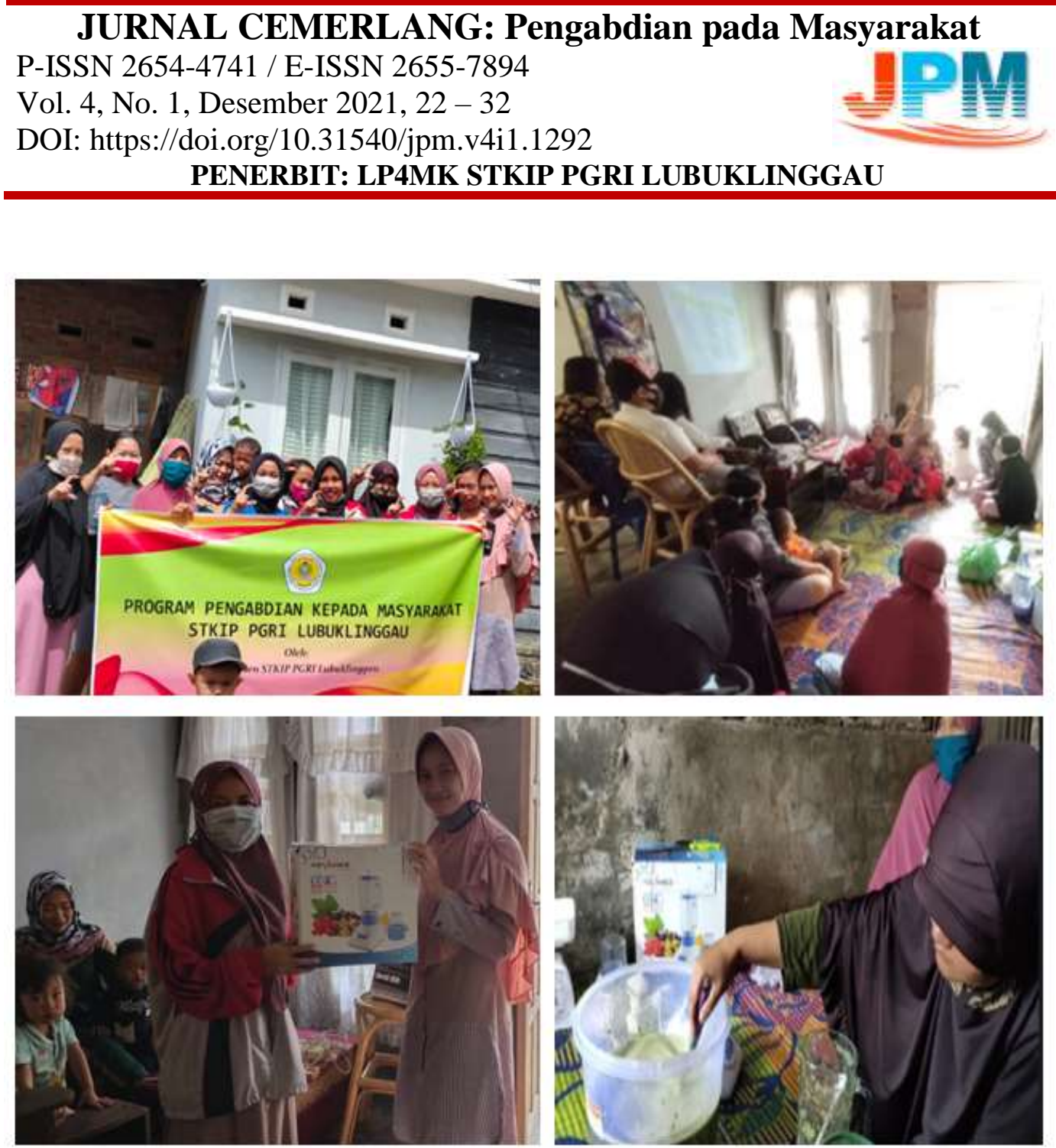

Gambar 4. Beberapa dokumentasi rangkaian kegiatan pengabdian

3. Mitra menghasilkan produk berupa ZPT alami. Dari kegiatan pengabdian ini diperoleh produk berupa ZPT dari bahan alami yang ada di lingkungan sekitar mitra. Adapaun bahan baku yang digunakan dalam pembuatan ZPT ini antara lain: air kelapa, gula, EM4, bawang merah, kecambah, rebung bambu dan pucuk-pucuk daun muda. Sedangkan alat yang digunakan adalah: blender untuk menghaluskan bawang merah, kecambah dan rebung bambu (jika tidak ada blender bahan juga bisa ditumbuk secara maual sampai bahan halus), pisau dan talenan untuk mencacah bahan baku agar lebih mudah dihaluskan, toples plastik untuk wadah fermentasi bahan baku yang sudah dicampur, spatula kayu sebagai pengaduk, corong dan botol plastik untuk pengemasan produk. Semua bahan yang dihaluskan 


\section{JURNAL CEMERLANG: Pengabdian pada Masyarakat \\ P-ISSN 2654-4741 / E-ISSN 2655-7894 \\ Vol. 4, No. 1, Desember 2021, 22 - 32 \\ DOI: https://doi.org/10.31540/jpm.v4i1.1292 \\ PENERBIT: LP4MK STKIP PGRI LUBUKLINGGAU}

dicampurkan ke dalam toples yang sudah berisi air kelapa, gula dan EM4 kemudian diaduk rata. Tutup rapat toples dan fermentasi selama 2-3 minggu. Setelah 3 minggu dilakukan penyaringan dan pengendapan terlebih dahulu agar cairan ZPT yang dihasilkan bening dan bersih dari ampas, kemudian kemas kedalam botol palstik. Produk yang dihasilakn ini dipasarkan oleh anggota PKK secara langsung maupun melalui social media.

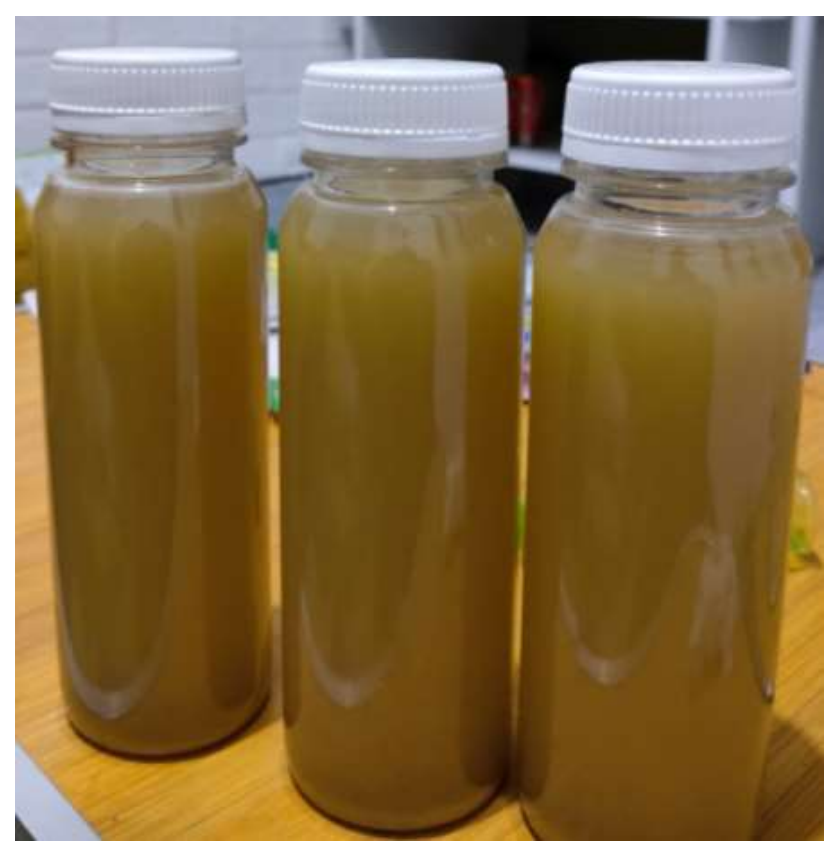

Gambar 5. Produk ZPT yang sudah dikemas dalam botol plastik

Rencana tahapan selanjutnya yang akan dilaksanakan oleh tim pengabdian masyarakat yaitu melakukan evaluasi keberhasilan dan keberlanjutan program. Kegiatan ini bertujuan untuk memantau pelaksanaan kegiatan yang dilakukan oleh mitra mulai dari pembuatan produk hingga ke pemasarannya. Saat ini tim PKM sedang mengupayakan melihart perkembangan pemasaran dan pembuatan desain produk yang aman dan bisa menarik minat konsumen.

\section{SIMPULAN}

Dari program pengabdian masyarakat yang telah dilaksanakan dapat disimpulkan bahwa mitra memiliki pengetahuan tentang bahaya bahan kimia dan 


\section{JURNAL CEMERLANG: Pengabdian pada Masyarakat \\ P-ISSN 2654-4741 / E-ISSN 2655-7894 \\ Vol. 4, No. 1, Desember 2021, 22 - 32 \\ DOI: https://doi.org/10.31540/jpm.v4i1.1292 \\ PENERBIT: LP4MK STKIP PGRI LUBUKLINGGAU}

peluang bahan alami di lingkungan sekitar tempat tinggal mitra menjadi produk yang memiliki nilai jual sehingga dapat meningkatkan perekonomian mitra pada khususnya dan masyarakat pada umumnya. Kegiatan pelatihan dan pendampingan menjadikan mitra mampuan serta terampil dalam memproduksi ZPT alami, selain itu mitra bisa menghasilkan produk yang memiliki nilai ekonomi dan memiliki pengetahuan tentang teknik pemasaran produk yang dihasilkan dan cara pengeloaan modal dan laba yang diperoleh dari hasil penjualan produk.

\section{DAFTAR PUSTAKA}

Patmasari \& Amarullah. (2020). Kajian Penggunaan Beberapa Bahan Alami Sebagai Sumber ZpPT dan Metode Sayatan Terhadap Sambung Pucuk Durian (Durio zibethinus Murr.). J-PEN Borneo: Jurnal Ilmu Pertanian Volume 3, Number1, April 2020Pages: 28-33E-ISSN: 25992872P-ISSN: 2549-8150 DOI : https://doi.org/10.35334/jpen.v3il.

Pemkab Rejang Lebong. (2017). Bupati Ajak Masyarakat Di Sekitar Objek Wisata Untuk Membangun Homestay. http://www.rejanglebongkab.go.id/bupati-ajak-masyarakat-di-sekitarobjek-wisata-untuk-membangun-homestay/(diakses: 25 Januari 2021)

Rahayu A A D, Riendriasari S D. (2016). Pengaruh Beberapa Jenis Zat Pengatur Tumbuh Terhadap Pertumbuhan Stek Batang Bidara Laut (Strychnos ligustrina BI.). Jurnal Perbenihan Tanaman Hutan, 4 (1): 25-31. 